Artigo recebido em

27/02/2014

Aprovado em

$15 / 03 / 2014$

ELIZA BACHEGA

CASADEI

Universidade Estadual Paulista Júlio de Mesquita Filho (UNESP)

Doutora em Ciências da

Comunicação pela Escola de Comunicações e Artes da Universidade de São Paulo (ECA-USP) e professora da Faculdade de Arquitetura, Artes e Comunicação da Universidade Estadual Paulista Júlio de Mesquita Filho (FAAC-UNESP). Email: elizacasadei@yahoo.com.br.
Estudos em Jornalismo e Mídia

Vol. $11 \mathrm{~N}^{\circ} 1$

Janeiro a Junho de 2014 ISSNe 1984-6924

\section{A Ditadura Militar Revisitada de 10 em 10 anos Através de Imagens: as fotografias de arquivo e a urdidura das reportagens de rememoração ${ }^{1}$}

Eliza Bachega Casadei

\section{Resumo}

Posto que o documento fotográfico sempre traz as marcas de um determinado universo imaginado, sujeito à ficcionalidade inerente a todas as montagens de enredo enquanto ato, o objetivo do presente artigo é analisar as fotografias de arquivo divulgadas nas matérias de rememoração da ditadura militar brasileira na revista Veja, publicadas nos aniversários decenais do golpe de 1964, a partir dos pressupostos metodológicos da retórica da imagem. Se, em alguns casos, as fotografias de arquivo reforçavam a argumentação da reportagem, em outros, elas criavam uma narrativa paralela, enquadrando o presente a partir de um passado interpretado.

Palavras-chave

Fotografia, Reportagem, Golpe Militar.

\begin{abstract}
Since photographic document always bears the marks of a given universe imagined, subject to fictionality inherent in all assemblies plot as an act, the purpose of this article is to analyze the photographs archival materials disclosed in remembrance of the Brazilian military dictatorship in the magazine Veja, published in the decennial anniversaries of the 1964 coup, from the methodological assumptions of the rhetoric of image. If, in some cases, archival photographs reinforced the argument of the report, in others, they created a parallel narrative, framing the present through an interpreted past.
\end{abstract}

Keywords

Photography, Reportage, Military Coup.

1- Uma versão modificada deste artigo foi enviada para o 3 o Encontro Regional Sudeste de História da Mídia, realizado entre os dias 14 e 15 de Abril na Universidade Federal do Rio de Janeiro (UFRJ). 
Fragmentos do passado

no presente: a lógica

argumentativa das

imagens de arquivo no

jornalismo

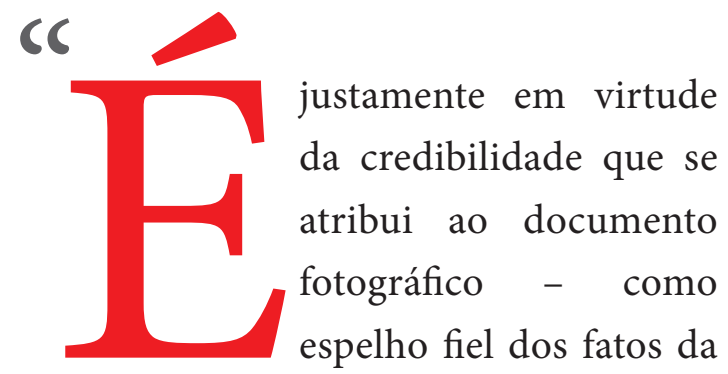

história cotidiana - que (...) poder-se-á dar margem à criação de um passado que jamais existiu", de forma que "a ficção pode então substituir o real, tendo o documento fotográfico como prova convincente, como constatação definitiva de legitimação de todo um ideário" (KOSSOY, 2005, p. 45).

A relação entre fotografia e o decorrido pode ser lida, sob essa perspectiva, a partir de uma chave dupla: se por um lado "toda fotografia que apreciamos se refere ao passado" (KOSSOY, 2005, p. 42), na medida em que se trata de uma representação que não é mais do que o congelamento de um determinado instante decorrido, seja ele próximo ou distante, por outro, a fotografia também é constantemente reinserida em outros contextos que lhe fornecem outros circuitos narrativos - circuitos narrativos estes alheios ao contexto em que a própria fotografia foi tirada, criando uma outra cena simbólica para este ocorrido que lhe serviu de objeto.

Se o próprio documento fotográfico, por mais referencial, sempre traz as marcas de um determinado universo ficcional, imaginário (no sentido de construído por escolhas múltiplas e resultantes de seu estatuto enquanto prática representacional), dificilmente a fotografia é apresentada de forma isolada na imprensa: reinserida em um contexto narrativo específico, a apropriação das fotografias de arquivo pelo jornalismo está sempre relacionada a uma determinada montagem de enredo que insere essas fotografias em uma outra história, sujeita à própria ficcionalidade inerente a todas as montagens de enredo enquanto ato.

As escolhas de determinadas fotografias de arquivo específicas (em meio a todas as fotos de arquivo possíveis), o modo como essas imagens se inserem na narrativa mais ampla da reportagem, bem como a relação estabelecida entre essas imagens elegidas e as outras fotografias postas na matéria são elementos que levam a essa reescrita do passado através de imagens - e que, se retomarmos os dizeres de Kossoy (2005), podem levar a uma urdidura de enredo que remete a um passado que nunca existiu.

Diante disso, o objetivo do presente artigo é analisar as fotografias divulgadas nas matérias de rememoração da ditadura militar brasileira na revista Veja, publicadas nos aniversários decenais do golpe de 1964. Dessa forma, serão analisadas as matérias rememorativas das edições de 03/04/1974, 04/04/1984, 30/03/1994 e 31/03/2004.

Todas as fotografias presentes nessas reportagens são fotografias de arquivo. Neste artigo, iremos estudá-las sob a perspectiva teórico-metodológica da retórica da imagem, com o objetivo de entender quais foram os mecanismos retóricos utilizados na reapropriação dessas imagens para o enquadramento de acontecimentos do tempo presente. 
Em cada uma dessas ocasiões, as reportagens da revista Veja conferiram ao golpe de 1964 diferentes interpretações sobre o seu significado, bem como diferentes consequências deste para a atualidade.

As imagens escolhidas para figurar nas reportagens em questão, em determinados casos, seguiram uma argumentação coerente com o texto tecido e, em outros, inauguraram uma narrativa própria e paralela - narrativa essa que, muitas vezes, remetia a aspectos da ditadura militar não tratados no texto da reportagem.

Neste artigo, iremos estudar justamente os mecanismos retóricos envolvidos nessa reapropriação jornalística das fotografias de arquivo e as narrativas históricas que são tecidas a partir desta reapropriação.

A comemoração pública, para Hobsbawm (2005), é um aspecto fundamental na construção de sentidos que são encampados para movimentos de luta - seja para assegurar um poder estabelecido, seja para contestá-lo. Ela cria laços e tem um papel importante na construção da coesão simbólica em torno de uma demanda. Rememorar o aniversário de um evento, portanto, é um ato político.

Comemorar estabelece laços entre um indivíduo e um universo simbólico mais abrangente relacionado a demandas específicas. Quando a imprensa rememora um aniversário, isso pode significar mais do que a simples atribuição de sentido ao passado; pode significar uma tomada de posição.

Nesse artigo, investigaremos os mecanismos retóricos a partir dos quais essa tomada de posição pode se dar através das fotografias de arquivo escolhidas nas matérias de aniversário decimais do golpe de 1964.

\section{$O$ regime militar revisitado por imagens de dez em dez anos}

As matérias comemorativas, para Edy (1999), fornecem uma espécie de fórum público de discussão para a atribuição de significado a um passado comum. Uma vez que é patente o fato de que nem

\section{Conforme o uso da fotografia na narrativa,}

\section{produz-se memória ou reescreve-se o passado}

todos os eventos que fazem aniversário em um determinado ano encontram espaço de comemoração na imprensa, a rememoração de um evento histórico na esfera midiática já é, portanto, em si, um instrumento de poder porque insere na esfera pública os acontecimentos que são dignos de serem lembrados.

É justamente a rememoração dos fatos históricos comuns que marca os acontecimentos fundadores das identidades comuns. E, a partir disso, o enquadramento da memória opera o fechamento da narrativa em torno de um modelo identitário da comunidade, através de uma História que é ensinada, aprendida e celebrada. É a isso que Paul Ricoeur se refere quando fala 
do "temível pacto" que é estabelecido entre rememoração, memorização e comemoração (RICOEUR, 2007, p. 98). Nesse sentido, as comemorações dizem muito mais a respeito do presente em que estão inseridas do que do passado a que se referem.

$\mathrm{Na}$ revista Veja é possível perceber que as fotografias de arquivo da ditadura militar entram na lógica da rememoração, memorização e comemoração a partir do uso de diferentes estratégias argumentativas, motivadas pelas diversas interpretações que a revista dá ao período, conforme analisaremos a seguir.

\section{4: fotografia de arquivo como atribuição de sentido para personagens}

A edição que faz a reportagem rememorativa dos dez anos de ditadura militar, em abril de 1974, na Veja, tem como capa um fundo preto, com um grande X vermelho e a manchete, em letras brancas, dizendo "Décimo aniversário da Revolução". Em um texto que usa exclusivamente a palavra "Revolução" (ao invés de golpe) para caracterizar o ato militar de 1964, a cobertura dos 10 anos de seu aniversário, em Veja, deve ser posta nesse contexto, já que a leitura da imagem da capa é polissêmica, podendo dizer respeito tanto ao algarismo dez em número romano, quanto a uma referência icônica à censura que a revista sofria na época.

Tal interpretação é reforçada na Carta ao Leitor publicada na ocasião que, em termos irônicos, lamentava a morte abrupta do padre Sean McIntosh, um personagem inventado pela redação: "Padre Sean, confesso, não existe, é um personagem de ficção jornalística, se me perdoam a expressão". Segundo o editor, Veja fez "dele o porta-voz de situações que, em certos momentos de atmosfera ionizada, não podem ser contadas". Ele afirma ainda que "a partir desta edição", esses personagens fictícios desapareceriam das páginas de Veja, "onde a redação se orgulhou em mantê-los tanto quanto hoje se alegra em despedi-los, pois não há nada pior, para um jornalista, que usar uma linguagem simbólica para contar os fatos. Talvez os leitores se alegrem conosco, ao detectar a boa qualidade de uma mudança que, no caso, desobriga Veja de incursões pela ficção" (VEJA, 03/04/1974).

De fato, trata-se de um período conturbado para Veja. A revista foi alvo de censura durante oito anos, de 1968 a 1976. Em um primeiro momento (de 1968 a 1973), a ação da censura era esporádica e mais flexível em comparação à sua ação em outros órgãos de imprensa. De 1974 a 1976, há um endurecimento da atuação dos órgãos censórios na revista. De março de 1973 a janeiro de 1974, a censura se voltava, principalmente, para matérias sobre a sucessão presidencial. De fevereiro a março de 1974, há um endurecimento do procedimento com censura prévia total e, a partir de abril, há censura branca (GAZZOTTI, 1999) - fato este expresso pelo editorial em questão.

A tônica argumentativa da reportagem especial rememorativa dos dez anos é a de que muitos interesses diferentes articularam o golpe militar, o que pode ser resumido na seguinte passagem:

A história das articulações que levaram à derrubada do governo João Goulart, em abril de 1964, tem tantos começos, praticamente, 
quantas forem as cabeças que dela participaram e, dez anos depois da vitória, que a todos espantou pela facilidade com que foi conquistada, os depoimentos se cruzam e chocam, numa tentativa de consolidar iniciativas para a eternidade histórica (VEJA, 03/04/1974).

Os motivos do golpe são expostos nos termos de que "a sua preocupação principal era a segurança da propriedade e dos negócios, cotidianamente ameaçada pela agitação das massas urbanas $\mathrm{e}$ rurais, e as ameaças de leis e decretos, cada vez mais radicais, com que de Brasília o presidente e seus partidários no Congresso Nacional bombardeavam o país" (VEJA, 03/04/1974).

Embora a reportagem não faça afrontas diretas ao regime militar, há certa insistência na divergência de interesses e críticas veladas à condução dos fatos políticos. Em outro trecho, a reportagem afirma que "a desvinculação do movimento de todas as pessoas, civis ou militares, que despontem como líderes de ideias próprias, parece ser a meta perseguida com mais afinco nesses dez anos" (VEJA, 03/04/1974). No fim da reportagem, há um chamado pela volta da normalidade democrática.

O especial é acompanhado, ainda, de outros textos de análise voltados ao significado dos dez anos de intervenção militar na política, em áreas específicas como economia, conflitos sociais e diplomacia.

É interessante notar, contudo, a forma como essa linha argumentativa se articula às fotografias publicadas pela edição.

A fotografia que abre a reportagem vem acompanhada da legenda "No Rio de Janeiro, a festiva marcha pelas ruas comemorando a derrubada de João
Goulart”. A multidão representada, fotografada na ocasião da "Marcha da Família com Deus pela Liberdade", enquadrada de cima para baixo, vaza os limites da fotografia, dando a sugestão de grandiosidade do evento retratado, tal como "se a imagem inteira fosse demasiado vasta ou complicada para ser captada em sua totalidade" (MASCELLI, 2010, p. 258) e remetendo também a um grande senso de organização. No centro da imagem, há faixas com os dizeres "Vitória da Democracia".

O texto da reportagem é entrecortado por quatro páginas de fotografias, em um total de vinte imagens, sob um plano de fundo preto, cujo objetivo era mostrar "os principais momentos da Revolução" (VEJA, 03/04/1974). Entre as legendas, é possível ler "Mourão e suas tropas chegam ao Rio", "O Alto Comando edita o AI-1" ou "Castello assume o governo no dia 11 de abril de 1964".

Essas imagens possuem algumas características composicionais comuns que sugerem uma narrativa imagética bastante clara, urdida a partir das fotografias históricas escolhidas. A narrativa tecida pelas imagens se desenvolve de forma autônoma e completamente alheia ao texto da reportagem.

No que diz respeito à representação do governo, é possível perceber que, em todas as fotografias, os apoiadores do golpe militar são representados de forma grandiosa e com uma forte sugestão de organização. Entre elas, há uma fotografia que representa Olímpio Mourão Filho, por exemplo, cercado por apoiadores, em um leve contre-plongée, com bandeiras do Brasil ao fundo. Em outras fotos, nas composições, os militares coadjuvantes 
são mostrados enfileirados, de maneira organizada, em imagens que valorizam um equilíbrio simétrico e uma sugestão de força e disciplina. Entre as fotografias dos presidentes militares, há também uma valorização do personagem: mesmo na fotografia que representa a doença de Costa e Silva, ele é mostrado de costas, em uma postura orgulhosa sugerida pela iluminação lateral em sua figura. Médici é representado de forma bastante simpática, jogando uma bola de futebol invisível no Planalto.

Outros atores sociais também são mostrados em algumas fotografias, embora em número bem menor: das vinte fotografias publicadas, apenas sete representam um lado que poderia ser chamado de opositor ao regime militar. Essas fotografias também possuem características composicionais comuns que, por sinal, diferem das características descritas anteriormente.

Em uma delas, mostra-se João Goulart, com uma feição abatida, cercado por militares, com a legenda "Jango recusa os conselhos de Brizola para resistência e foge para o Uruguai”. Em outra, há uma imagem da passeata dos cem mil, tirada em grande plano geral e, ao seu lado, uma fotografia de Carlos Lacerda e Juscelino Kubitschek em um jantar, organizando a Frente Ampla, e outra de Márcio Moreira Alves abraçando a mãe. Abaixo, é possível ver uma manifestação estudantil que culminou em confronto com a legenda "o terror e a violência nas ruas do Rio e São Paulo em 1968: as manifestações estudantis como uma forma de protesto". Nessa fotografia, contudo, embora seja possível ver dois homens lutando caídos no chão (um deles segurando uma arma) e um outro, em pé e na mira do revólver, também brigando com os outros dois, não é possível identificar a identidade funcional de nenhum deles (a fotografia do homem com a arma, bem como dos outros dois, não se identifica nem a um policial, nem a um estudante; são apenas homens lutando).

Há também uma fotografia do embaixador sequestrado Burke Elbrick, já resgatado e em segurança. Por fim, a última fotografia mostra a morte de Carlos Marighella. Ao contrário da distância respeitosa imposta na imagem da doença de Costa e Silva, o corpo de Marighella é mostrado em close. Esses dois conjuntos de representações fotográficas escolhidos deixa entrever de maneira clara a narrativa imagética articulada pela revista nessa reportagem de rememoração dos dez anos da ditadura militar: apesar de o texto tecer críticas pontuais, as fotografias engrandecem os apoiadores do regime, ao mesmo tempo em que tratam de maneira indiferente ou distante os atores sociais que eram abertamente contra a política instaurada.

$\mathrm{Na}$ narrativa imagética, tecida independentemente do texto, é possível ver a categorização clara de personagens: de um lado, os apoiadores do regime militar, cujas fotografias de arquivo escolhidas sugeriam um equilíbrio simétrico e um grande senso de organização e, de outro, os opositores ao regime, mostrados de forma abatida, desorganizada ou abertamente desrespeitosa (como no caso do corpo de Marighella).

As imagens não apenas não dialogam com a narrativa tecida pela reportagem, como também urdem uma narrativa própria. 


\section{4: fotografias de arquivo como analogia}

Em 1984, a tônica da reportagem de rememoração dos vinte anos é bastante diversa. Com a manchete "A velhice aos 20 anos" e a linha-fina "O regime de 1964 tornou-se um sonho quebrado". A argumentação do texto reforça a ideia de que "após vinte anos, se voltou ao ponto de partida" no que diz respeito aos problemas identificados, com uma diferença: "a certeza de que não se conseguirá resolvê-los com a força das armas" (VEJA, 04/04/1984). Para Veja, "as datas históricas raramente querem dizer alguma coisa. Os vinte anos da revolução significam apenas que o regime sobreviveu a muitos prazos para acabar, e tanto se esticou para durar que se deformou a ponto de ficar irreconhecível".

A mudança da argumentação textual é acompanhada por um tratamento bastante diverso dado às imagens de arquivo. A reportagem traz duas montagens fotográficas. Na primeira, os presidentes militares são postos lado a lado, enquadrados pouco abaixo da altura dos ombros, contra um fundo escuro. Ao contrário das fotografias de arquivo engrandecedoras escolhidas na rememoração dos dez anos, foram feitas opções que retratavam os presidentes militares de forma sombriamente apática, com suas silhuetas projetadas contra um fundo cinzento.

Em termos argumentativos, é possível dizer que tal fotografia possui uma clara função pathética. A partir da noção de que as paixões podem ser mobilizadas pelo discurso e são capazes de serem estimuladas sob a força de argumentos, o pathos diz respeito justamente ao elemento da retórica referente às emoções despertadas no leitor a partir de um conjunto de técnicas discursivas mobilizadas pelo narrador. A partir do pressuposto de que "quando as pessoas sentem-se afáveis e tolerantes, elas pensam num determinado tipo de coisa, mas quando estão furiosas e

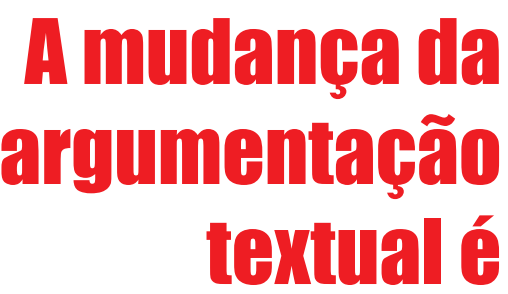
companhada por um tratamento bastante diverso dados às imagens de arquivo

hostis, pensam essa mesma coisa numa intensidade diferente ou pensam em algo totalmente diferente" (ARISTÓTELES, 2007, p. 81), o pathos, portanto, trata do modo como o orador pode despertar, convenientemente, determinadas disposições de espírito em seu auditório, determinados excessos emocionais que influenciam o julgamento em torno do narrado.

Como aponta Fiorin (2004), o pathos diz respeito a uma projeção discursiva do enunciatário, em oposição a um estado de espírito empírico, na medida em que determina as escolhas linguísticas por parte do enunciador - no sentido já trabalhado por Eco (2002), de que a escolha de um leitor-modelo implica na própria adoção de um autor-modelo - e, mais do que isso, de uma projeção que 
tem como alvo central a afetividade e o excesso emotivo por meio de técnicas argumentativas empregadas a partir dessa projeção.

Retratar os presidentes militares de uma forma sombria colabora retoricamente com o tom adotado no texto da reportagem: o excesso emotivo evocado nos elementos icônicos e discursivos da fotografia contribui com a eficácia da argumentação pretendida no nível textual. Ali, os presidentes militares são representados de forma taciturna e lúgubre, contribuindo com o tom adotado no texto.

A segunda montagem fotográfica presente na reportagem é composta por duas fotografias: de um lado, assim como na rememoração dos dez anos, há uma imagem da "Marcha da Família com Deus pela Liberdade", posta ao lado de uma fotografia da campanha das “Diretas Já. Diferentemente da fotografia escolhida anteriormente, contudo, há uma mudança sensível na forma de representação do evento. Embora os manifestantes da "Marcha da Família com Deus pela Liberdade" estejam empunhando uma série de cartazes, em nenhum deles é possível ler a palavra "Democracia" - palavra esta que estava posta em um cartaz enquadrado no centro da imagem na rememoração dos dez anos. Nos cartazes, podemos ler frases como "Marcha da Família Cristã" ou "Campanha de Educação". A palavra "Democracia” está enquadrada nas faixas carregadas pelos manifestantes presentes na segunda fotografia, a da "Diretas Já", além de expressões como "Optei por eleições livres e diretas".

A massa presente na fotografia das Diretas Já também parece grande e compacta, ao passo que (diferentemente da imagem escolhida na rememoração dos dez anos) as pessoas retratadas na Marcha da Família com Deus pela Liberdade parecem menos unidas e com maior espaçamento entre elas.

Se a primeira montagem fotográfica tem uma importante função no estabelecimento do pathos da reportagem, dando um clima emocional ao texto, a segunda articula uma função argumentativa de comparação clara entre uma situação do passado e um evento do presente. Nesse caso, é possível notar que o presente é medido pelo passado a partir de uma similitude de relações, nos termos de uma analogia.

As analogias históricas não são meras figuras de comparação entre uma situação do passado e um acontecimento do presente. De acordo com Perelman (1997), as analogias são figuras retóricas que constroem uma estrutura do real que permite provar uma verdade graças a uma semelhança de relações. Ela não se limita a uma simples similitude entre termos, ou seja, "se afirmarmos que A é B (esse homem é uma raposa), não se tratará, pois de uma analogia, e sim de uma metáfora" (PERELMAN, 1997, p. 334). A analogia também difere de outros tipos de enquadramento, como a ilustração ou o exemplo, porque esta relação que ela estabelece se dá entre áreas diferentes e que não podem ser subsumidas de uma estrutura comum.

O esquema da analogia pode ser descrito a partir da afirmação de que A está para B assim como C está para D. Perelman explica que é fundamental que o primeiro par (A-B) seja menos conhecido do que o segundo, que o deve estruturar graças à analogia. Desta forma, 
elas deslocam a adesão do indivíduo ouvinte daquilo que é conhecido para o que é desconhecido.

Neste mesmo sentido, Breton (1999) esclarece que os argumentos analógicos implicam um raciocínio que suponha ou que invente um vínculo entre duas zonas do real. Este vínculo, no entanto, não se faz ao longo de uma cadeia contínua. Ele se constrói em um espaço descontínuo através do qual os enunciados se permitem alguns saltos (que dificilmente seriam justificáveis em outras circunstâncias). "A ponte lançada entre as duas zonas do real se justifica assim apenas porque ela permite passar de uma margem a outra" (BRETON, 1999, p. 131).

A analogia está estruturada a partir de uma transferência de valor do conhecido para o que está com o sentido em disputa. No caso de reportagens que utilizam argumentos históricos, o conhecido, usualmente, está estruturado em torno do decorrido e a similitude de relações é a responsável por estabelecer direções de sentido para os acontecimentos do presente. Ao estabelecer uma relação de semelhança entre duas coisas que inicialmente estavam separadas, a analogia histórica se torna um recurso comum nos jogos de produção de sentido na construção das reportagens jornalísticas.

No caso da reportagem de rememoração dos vinte anos da ditadura militar no Brasil, é possível notar que essa similitude de relações é estabelecida na própria fotografia, ao estabelecer uma relação de semelhança entre um fato de passado e uma situação do presente.

A comparação estabelecida por meio de imagens reforça a argumentação do texto de que a história estaria se processando de maneira circular, de forma que o julgamento das Diretas Já (presente) é medida segundo as regras do passado.

\section{4: fotografias de arquivo como marcas de disjunção do início e do fim}

Em 1994, novamente o entendimento de Veja sobre o regime militar segue uma outra linha. Além de usar a expressão "golpe de 1964" ao invés de "Revolução de 1964", de forma diversa das rememorações anteriores, a linha argumentativa se volta para a questão, exposta na linha fina, de que "deflagrado num rompante de dois generais de segundo escalão, o golpe de 1964 se consolidou por inércia e sem enfrentar resistência” (VEJA, 30/03/1994). De acordo com o texto: "nenhum militar foi morto em confronto, mesmo porque os fardados não se encaravam em nenhuma batalha. Cenas de violência, pouquíssimas, aconteceram contra civis, em sua maioria, no Nordeste. (...) Foi fácil derrubar a democracia no Brasil de trinta anos atrás. Aquele era um país exausto. Estava dividido" (VEJA, 30/03/1994).

As fotografias que acompanham essa reportagem, assim como na reportagem rememorativa dos dez anos, também tentam evocar os principais acontecimentos do período de 30 anos. A articulação retórica e narrativa, contudo, se urde de forma diversa. Ao contrário das fotografias que evocam um alto senso de organização dos militares, as imagens de arquivo escolhidas mostram os militares de forma mais desorganizada e caótica. As fotografias que evocam a tomada de 
Rio de Janeiro já não mostram os militares organizados, mas sim, aglomerados ou dispersos. Além disso, a fotografia que mostrava Jango no exílio com um rosto abatido é substituído por um retrato mais lisonjeiro do ex-presidente, recostado a uma parede e sozinho em uma postura mais heroica e orgulhosa (sem os militares cercando-o, como a fotografia que ilustrava a rememoração dos dez anos). Também há uma foto da sede da União Nacional dos Estudantes (UNE) incendiada, o que corrobora a iconografia de desorganização dos militares.

A narrativa organizada, portanto, é bastante diversa da evocada na rememoração dos dez anos: vinte anos depois, é o senso de desorganização do governo que prevalece na iconografia das fotografias de arquivo selecionadas.

Em outro texto, publicado na mesma edição com o título "A Grande Trapaça", esse sentido é reforçado: nessa reportagem, Veja afirma que "nascido com a desculpa de defender a democracia, o regime de 1964 conseguiu eliminá-la”. Curiosamente, é a análise de uma fotografia que abre a reportagem:

É útil prestar atenção na fotografia que se encontra na página 4 desta edição, onde fica o índice de Veja. Mostra-se, ali, uma passeata que reuniu 200000 pessoas e desfilou pelas ruas no Rio de Janeiro. Vale a pena saber quais são as palavras de ordem das faixas e cartazes. "Reformas com democracia". "Liberdade". Uma que diz "Ditadura nunca!”. Não é uma manifestação pelas diretas já de 1984. É a Marcha da Vitória, ocorrida duas décadas antes, no dia 2 de abril de 1964, quando uma multidão saiu às ruas para comemorar a queda de Goulart e apoiar o novo regime. (VEJA,
Por fim, a reportagem conclui que "na realidade, as ditaduras se produzem quando aparecem governantes que consideram que o país inteiro, na economia e na política, em sua vida cultural e mesmo nas relações pessoais entre os cidadãos, viverá melhor sob um regime de forma do que numa democracia. É uma visão de mundo, e não um acidente". E, assim, "por esse motivo, em 1964 um regime instaurado sob a promessa de promover um breve retorno à democracia levou vinte anos para acabar. Houve grandes manifestações quando Jango caiu. Mas a festa foi muito maior quando os militares foram embora" (VEJA, 30/03/1994).

Curiosamente, a fotografia citada na reportagem não é mostrada novamente ao leitor (ele deveria voltar às páginas até o sumário para visualizá-la novamente). As duas fotografias presentes na matéria, contudo, marcam de forma clara a argumentação pretendida pela revista. São apenas duas imagens: na primeira (lado direito da página) é mostrada a posse de Castello Branco, com todos os militares enfileirados organizadamente, em uma postura grandiosa; a segunda, (do lado esquerdo) mostra a famosa foto de Figueiredo, decrépito, sentado em uma cadeira. Nas legendas, lê-se "o começo com Castello, em 1964, e o fim com Figueiredo, em 1985: material para reflexão" (VEJA, 30/03/1994).

A iconografia não poderia ser mais sugestiva: em conjunção com o texto da reportagem, as fotografias montam uma narrativa de um começo glorioso e de um fim decrépito, de forma que o significado da fotografia anterior 
influencia no sentido da fotografia posterior, estabelecendo uma metáfora imagética do momento histórico.

Entre essas duas imagens, é possível perceber que a reportagem estabelece uma metáfora in praesentia disjunta, em que as duas entidades comparadas (as duas fotografias) ocupam lugares diferentes (são fotografias diferentes, sem justaposição nem substituição na própria imagem), mas que estabelecem um emparelhamento de iconografias que estabelecem os termos da comparação. O fim e o começo são ligados em uma narrativa imagética coerente, que convoca o leitor a preencher os espaços em branco presentes no período que medeia o clique entre as duas fotografias.

\section{4: fotografia de arquivo como instauradora de uma narrativa paralela}

No aniversário de 40 anos do golpe de 1964, Veja desloca a ênfase de sua argumentação para os sucessos econômicos obtidos pelo regime militar, bem como os erros estratégicos que minaram parte desse crescimento. A maior parte das fotografias reforça justamente essa argumentação: em um total de três imagens, uma delas mostra a posse de Castello Branco, outra mostra a Usina de Itaipu e a última a Central de Chamadas em São Paulo para simbolizar os investimentos em telefonia.

Uma construção imagética mais interessante está presente no texto seguinte, "Eles ainda estão por aí". Nele, Veja argumenta que "vícios e deformações do período militar são visíveis ainda hoje no cenário político". De acordo com a reportagem, "a herança mais evidente dos 21 anos de ditadura militar não está no que o regime criou, mas, sobretudo, no que impediu que funcionasse $\mathrm{e}$ evoluísse, como o surgimento de novos líderes, a ampliação do eleitorado ou a sintonia do sistema partidário com a crescente complexidade da sociedade". E, assim, "o regime militar provocou um imenso atraso na evolução da cultura política brasileira", "o tratamento dado às questões políticas, em vez de basear-se na racionalidade, no debate, na divergência sadia, descambou para a tortura" e "os partidos políticos não nasceram como canais de expressão de certos segmentos sociais, razão pela qual a maioria das legendas carece de identidade social" (VEJA, 31/03/2004).

$\mathrm{Na}$ primeira página da dupla que abre a reportagem, há a famosa fotografia de Costa e Silva sentado sozinho no Congresso Nacional e, na página ao lado, há a fotografia do ex-presidente Luiz Inácio Lula da Silva e da ex-primeiradama. A legenda desta foto justifica a sobreposição das fotografias com os dizeres: "Lula, ao lado de dona Marisa, na posse: PT surge como resultado da modernização do capitalismo".

Este sentido dado pela legenda, contudo, não é o único sentido que surge a partir da justaposição das duas fotografias: a aproximação da imagem do passado com a fotografia do presente estabelece novamente uma similitude de relações, que influencia a argumentação engendrada pela reportagem. Há nessa justaposição não apenas uma comparação explícita entre o governo Lula e o regime militar, como também uma comparação com um momento específico do regime, em que há um isolamento radical do poder executivo em relação ao poder 
legislativo.

Para Vogt, as construções argumentativas que colocam na balança dois dados com a intenção de medi-los quer expressem relações de concessão, de excesso ou de compensação (DUCROT, 2009 , p. 12) - se inserem no que ele chama de um intervalo semântico. Esse termo diz respeito a determinados elementos argumentativos que não correspondem a uma espécie de ideia em si, mas sim, a criação de uma orientação do discurso. Para este autor, o comparativo representa uma estrutura privilegiada do intervalo, uma vez que ele guarda em si a força primitiva de um julgamento que "antes de dizer o grau e a medida situa o homem diante do mundo e, de dentro desta situação, confunde-o na subjetividade do ponto de vista" (VOGT, 2009, p. 33). Este intervalo, no entanto, não se situaria entre os objetos que ele separa e busca comparar (contrariamente ao que a própria palavra intervalo parece sugerir). Ele assume uma relação constitutiva em relação a eles.

O que Vogt argumenta é o fato de que a maior parte das comparações a um mecanismo que diz respeito ao cotejamento entre elementos não possuem uma escala objetiva de valores para as qualidades comparadas. Quando eu digo que "Pedro é mais inteligente que João", por exemplo, não há um sistema de medida possível ou uma gradação que me permita situar os termos da comparação. Como explica Ducrot (2009, p. 14), nestes casos, "a confrontação surge então como um simples instrumento de descrição: a coisa não é aquilo que é senão por referência a uma outra”. Assim, a relação aqui não é derivada dos termos e, sim, os constitui. "A relação não está mais fora das coisas, mas nelas”.

$O$ que isso significa é que esta constituição assumida a partir da comparação dos termos não é de ordem factual, real ou mesmo uma condição prévia para a comparação. Ela é de ordem argumentativa. Ela "diz respeito não ao que é a inteligência de Pedro ou de João, mas ao que disso se deve concluir, às consequências que disso se devem tirar". Isso porque "através da comparação, lanço uma espécie de advertência à pessoa a quem me dirijo: não subestime a inteligência de Pedro (ou não superestime a de João)" (DUCROT, 2009, p. 17).

$\mathrm{Na}$ reportagem em questão, é possível ver que Veja estabelece esse mecanismo de argumentação a partir da narrativa imagética urdida. Em nenhum momento do texto da reportagem essa ideia é explicitada: a aproximação das imagens de arquivo com uma imagem do presente, contudo, não deixam dúvida quanto à argumentação urdida.

\section{Considerações Finais:}

O uso de fotografias de arquivo pela imprensa, frequentemente, reveste-se de um "dever lembrar-se". Para Ricoeur, o dever de memória diz respeito a um aspecto da memória em que ela é conectada diretamente ao conceito de "justiça”: é "a justiça que, ao extrair das lembranças traumatizantes seu valor exemplar, transforma a memória em projeto; e é esse mesmo projeto de justiça que dá ao dever de memória a forma do futuro e do imperativo." (RICOEUR, 2007, p. 101).

É a lógica interna desse "dever lembrar-se" que está presente no 
jornalismo rememorativo, posto que há uma tentativa de, a partir de lembranças traumatizantes, extrair alguns valores exemplares, algumas regras de conduta moral, orientando a ação para o futuro. Essas regras internas do "dever lembrarse" se estruturam em torno de: (1) a presença de um "outro" a quem se deve fazer justiça; e (2) o reconhecimento de uma herança. Portanto, "não se trata mais, obviamente, de manipulações no sentido delimitado pela relação ideológica do discurso com o poder, mas, de modo mais sutil, no sentido de uma direção de consciência que, ela mesma, se proclama porta-voz da demanda de justiça das vítimas." (RICOEUR, 2007, p. 102).

O uso das fotografias de arquivo está inserido nesse processo na medida em que, ao serem postos na reportagem, essas imagens se ligam a urdiduras de enredo específicas e que implicam na transformação dos fatos coletados na pesquisa em representações postas de acordo com uma organização que a caracteriza enquanto uma estória propriamente dita, que possua começo, meio, fim, bem como fases determinadas e um sentido dado pelas relações silogísticas estabelecidas entre os termos.

Nesse aspecto, as fotografias de arquivo adquirem uma função figurativa porque "enquanto os eventos acontecem no tempo, os códigos cronológicos utilizados para ordená-los em unidades temporais específicas são culturalmente demarcados, não naturais" - ou seja, estão postos em enredo. Nesse sentido, para White, o ato de articular a urdidura de enredo é sempre uma ação muito mais poética do que propriamente científica, na medida em que pressupõe esse tipo de mediação: "os eventos podem ser dados, mas as suas funções enquanto elementos de uma estória são impostas sobre eles - por técnicas discursivas que são mais tropológicas do que lógicas por natureza" (WHITE, 1999, p. 9).

As fotografias de arquivo nas reportagens de rememoração adquirem mesmo um valor de citação, posto que significam justamente ao "retirar um material já significante de dentro de um discurso para fazê-lo funcionar dentro de um novo sistema significante" (MAINGUENEAU, 2002, p. 125). E, ao fazê-lo, carregam consigo todo um valor simbólico acerca do sentido do evento que representam e da relação que este acontecimento estabelece com o tempo presente.

\section{Referências bibliográficas}

ARISTÓTELES. Retórica. São Paulo: Rideel, 2007.

BRETON, P. A Argumentação na Comunicação. Bauru: EDUSC, 1999.

DUCROT, O. "Prefácio". In VOGT, C. O Intervalo Semântico: contribuição para uma Teoria Semântica Argumentativa. São Paulo: Ateliê, 2009.

ECO, U. Lector in fabula: a cooperação interpretativa nos textos narrativos. São Paulo: Perspectiva, 2002.

EDY, J. “Journalistic Uses of Collective Memory”. Journal of Communication, v. 49, n. 2, 1999, p. 71-85. 
FIORIN, J. L. “O Pathos do Enunciatário”. Alfa, v. 2, n. 48, 2004, p. 69-78.

GAZZOTTI, J. Imprensa e Ditadura: a revista Veja e os governos militares (19681985). Dissertação (mestrado) - Universidade Federal de São Carlos. São Carlos: UFSCAR, 1999.

HOBSBAWN, E. Sobre História. São Paulo: Companhia das Letras, 2005.

KOSSOY, B. "Fotografia e Memória: reconstituição por meio da fotografia”. In SAMAIN, E. (org.). O Fotográfico. São Paulo: Hucitec, 2005.

MAINGUENEAU, D. Novas tendências em análise de discurso. Campinas: Pontes, 2002.

MASCELli, J. V. Os Cinco Cs da Cinematografia. São Paulo: Summus, 2010.

PERELMAN, C. e OLBRECHTS-TYTECA, L. Tratado de Argumentação: a nova retórica. São Paulo: Martins Fontes, 1996.

RICOEUR, P. A Memória, a História, o Esquecimento. Campinas: Editora da Unicamp, 2007.

VOGT, C. O Intervalo Semântico. São Paulo: Ateliê, 2009.

WHITE, H. Figural Realism: studies in the mimesis effect. Baltimore: The John Hopkins University Press, 1999.

Este artigo e todo o conteúdo da Estudos em Jornalismo e Mídia estão

disponíveis em https://periodicos.ufsc.br/index.php/jornalismo

Estudos em Jornalismo e Mídia está sob a Licença Creative Commons 2.5 